\title{
Tropical Fowl Mite, Ornithonyssus bursa (Berlese) (Acari: Macronyssidae) ${ }^{1}$
}

H. A. Denmark and H. L. Cromroy ${ }^{2}$

\section{Introduction}

The tropical fowl mite, commonly found on birds, has become a pest to man in areas of high bird populations or where birds are allowed to roost on roofs, around the eaves of homes, and office buildings. Nesting birds are the worst offenders. After the birds abandon their nests, the mites move into the building through windows, doors, and vents and bite the occupants.

The bite is irritating to man and some individuals react to the bite with prolonged itching and painful dermatitis. Several to many reports are received each year of mites invading homes. The mites are usually the tropical fowl mite found in the central and southern areas of the state. The northern fowl mite, Ornithonyssus sylviarum (Canestrini and Fanzago), a close relative, is also found in Florida.

\section{Synonyms}

Leiognathus bursa Berlese (1888)

Liponyssus bursa Hirst (1916)

Ornithonyssus bursa Sambon (1928)

\section{Distribution}

- Africa - Egypt, Nigeria, Malawi, Republic of South Africa

- Asia - China, India, Thailand. Indonesia - Java, Mauritius

- Australia - New South Wales, Queensland, South Australia

- Central America - Canal Zone

- Islands of the Indian Ocean - Comoro Islands, Zanzibar

1. This document is EENY-297 (originally published as DPI Entomology Circular 299), one of a series of Featured Creatures from the Entomology and Nematology Department, Florida Cooperative Extension Service, Institute of Food and Agricultural Sciences, University of Florida. Published: July 2003. This document is also available on Featured Creatures Website at http://creatures.ifas.ufl.edu. Please visit the EDIS Website at http://edis.ifas.ufl.edu. Additional information on these organisms, including many color photographs, is available at the Entomology and Nematology Department website at http://entnemdept.ifas.ufl.edu/.

2. H. A. Denmark, Florida Department of Agriculture and Consumer Services, Division of Plant Industry; and H.L. Cromroy, Department of Entomology and Nematology, University of Florida, Gainesville, FL.

The Institute of Food and Agricultural Sciences (IFAS) is an Equal Employment Opportunity - Affirmative Action Employer authorized to provide research, educational information and other services only to individuals and institutions that function without regard to race, creed, color, religion, age, disability, sex, sexual orientation, marital status, national origin, political opinions or affiliations. For information on obtaining other extension publications, contact your county Cooperative Extension Service office. Florida Cooperative Extension Service / Institute of Food and Agricultural Sciences / University of Florida / Larry R. Arrington, Interim Dean 


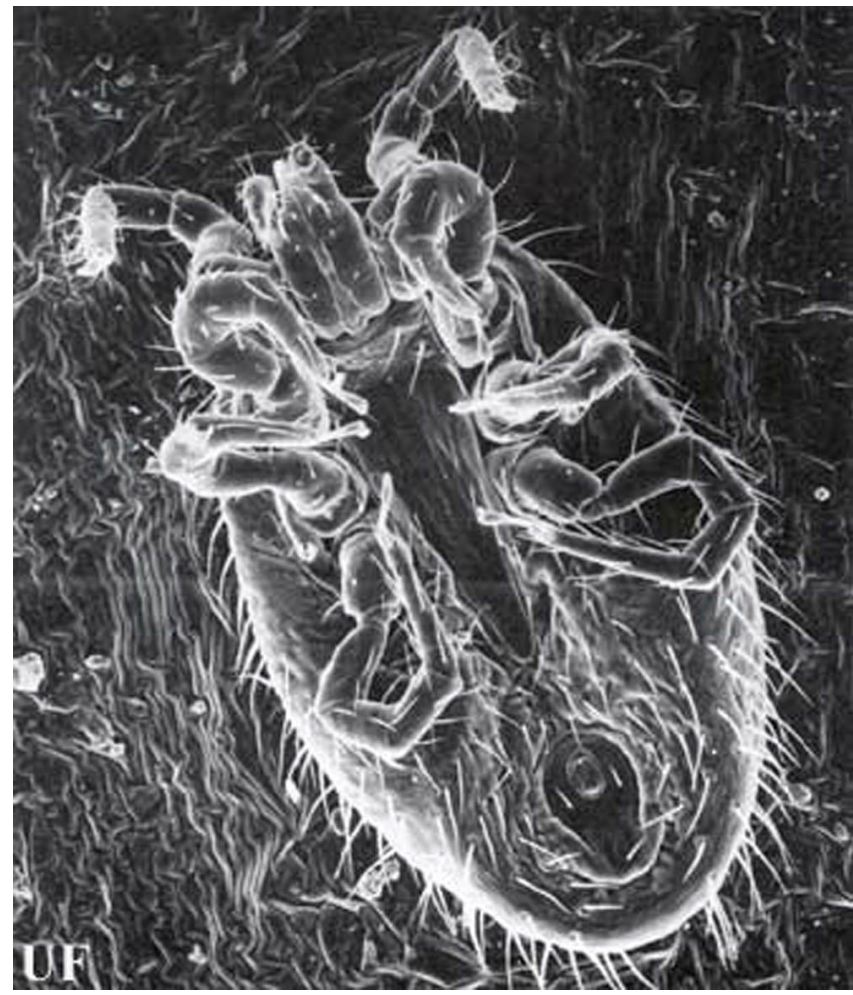

Figure 1. Scanning electron microscope (SEM) photograph showing ventral view of the tropical fowl mite, Ornithonyssus bursa (Berlese). Credits: H. L. Cromroy, University of Florida

- Islands of the Pacific - Hawaii, New Guinea

- North America - Canada, United States

- South America - Argentina, Colombia

- West Indies - Bahamas Islands

This mite is almost entirely restricted to warm and tropical regions. Canadian records could have been from birds returning from a warm region or a misidentification of the northern fowl mite.

\section{Description}

Although the tropical fowl mite is similar to the northern fowl mite, it can be separated by the dorsal plate. The posterior end tapers acutely in $O$. sylviarum but more evenly in $O$. bursa. There are three pairs of setae on the sternal plate in $O$. bursa and only two pairs in $O$. sylviarum.
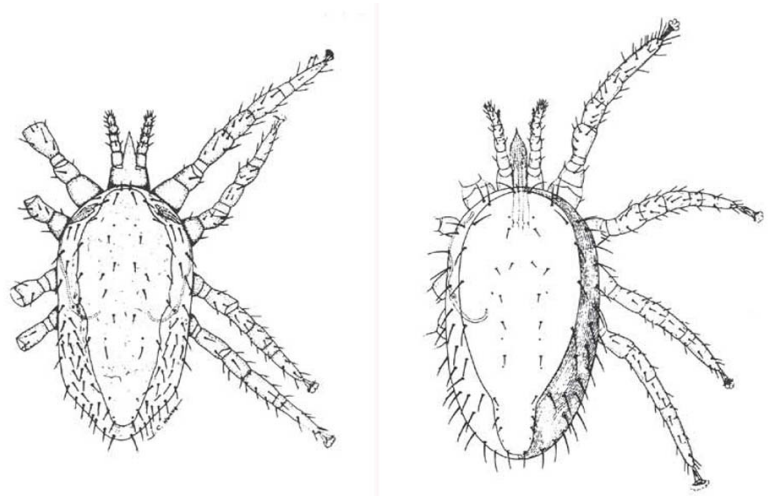

Figure 2. Dorsal views of the tropical fowl mite (left), Ornithonyssus bursa (Berlese); and the northern fowl mite (right), Ornithonyssus sylviarum (Canestrini and Fanzago). Credits: Division of Plant Industry (after Strandtmann \& Whatton)
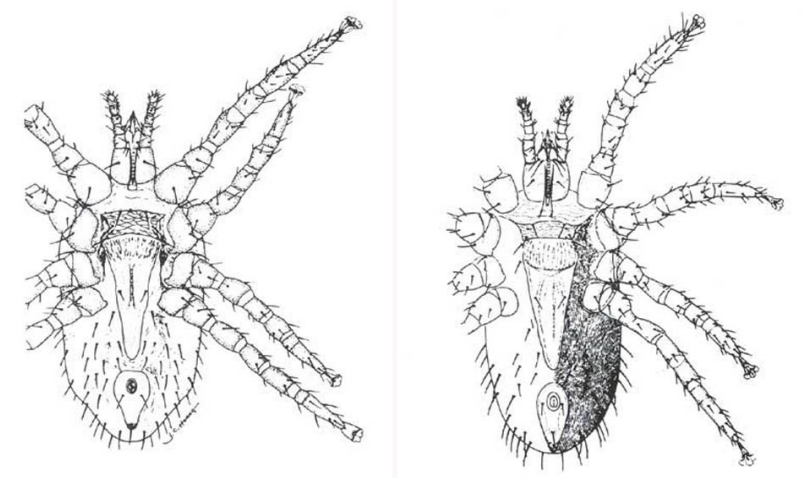

Figure 3. Ventral views of the tropical fowl mite (left), Ornithonyssus bursa (Berlese); and the northern fowl mite (right), Ornithonyssus sylviarum (Canestrini and Fanzago). Credits: Division of Plant Industry (after Strandtmann \& Whatton)

\section{Life Cycle}

This mite's life cycle is similar to the northern fowl mite. It has five stages - egg, larva, protonymph, deutonymph, and adult. In the laboratory, it lays most of its eggs in the litter away from its hosts. In the field, it lays its eggs on the host or in the nest. Eggs hatch within three days. The nonfeeding larvae molt in about 17 hours. The protonymph will molt in one or two days, but the length of the deutonymphal stage has not been determined. It is about a day in length in the northern fowl mite.

The nymphs and adults of the tropical fowl mite take blood meals as opposed to only the protonymph and adult stages in the northern fowl mite. On birds, most of the breeding takes place in the nests. Only a 
few mites are found on birds that are flying about. On chickens, the mites prefer the fluffy downy feathers and are numerous about the vent, accumulating on a few feathers. If a man handles the infested chicken he will become infested, since mites will move from chicken to man. This has occurred in the layer industry when there are heavy mite infestations.

\section{Hosts}

Mammals: bandicoot, gerbil, humans.

Birds: canaries, caracara, chickens, common sparrow, ducks, English starling, kingbird, meadowlark, pigeons, red-eyed vireo, turkey, wild birds, and wood thrush.

\section{Economic Importance}

The tropical fowl mite is a serious pest of domestic fowl and wild birds. It is almost never found on wild mammals although there are many records of it biting humans. It has never been implicated in vectoring diseases. Chamberlain and Sikes (1955) concluded, after exhaustive tests, the mite is unimportant as a reservoir or transmitter of equine encephalitides.

Attacks on man cause discomfort similar to that caused by Ornithonyssus sylviarum, northern fowl mite, which is also a pest of domestic fowl and wild birds. Other than bandicoots and gerbils it apparently does not attack other mammals except humans and this occurs only when a bird or fowl host is not available. The northern fowl mite is common in the north temperate zone, but also is found in Florida.

\section{Survey and Detection}

Look for nesting birds around the eaves of buildings. Remove nests and discourage birds from nesting in or on building. Secure all openings to attic, windows, and doors.

\section{Management}

In homes or commercial buildings, remove all bird nests and wash the walls with a strong spray of water or steam clean. In poultry layer operations, use synthetic pyrethroids. If the mites migrate into the home, a fumigant may serve as a good control agent.
Follow label directions. This mite can only live for about 10 days away from the bird hosts so its effect on man is temporary.

For more information see: Insect Management Guide for Mites that Attack Humans (http://edis.ifas.ufl.edu/IG086).

\section{Selected References}

Berlese A. 1882-1892. Acari, Myriapoda et Scorpiones hucusque in Italia reperta: Mesostigmata. Fusc. 52, No. 2, 143 pp.

Chamberlain RW, Sikes RK. 1955. Laboratory investigations on the role of bird mites in the transmission of eastern and western equine encephalitis. American Journal of Tropical Medicine and Hygiene 4: 106-1118.

Hirst S. 1916. On some new acarine parasites of rats. Bulletin of Entomological Research 6: 183-190.

Sambon LW. 1928. The parasitic acarions of animals and the part they play in the causation of the eruptive fevers and other diseases of man.

Preliminary considerations based upon an ecological study of typhus fever. Annals of Tropical Medical Parasitology 22: 67-132. 